\title{
ESTIMACIÓN ERÓTICA DEL AMOR CRISTIANO EN LAS CONFESIONES DE SAN AGUSTÍN ${ }^{a}$
}

\section{Erotic estimation of Christian love in the Confessions of Saint Agustin}

\section{Antículo de reflexión no derivado de investigación}

DOI: https://doi.org/10.21501/23461780.3844

Recibido: 7 de febrero de 2020 / Aceptado: 30 de noviembre de 2020 / Publicado: 14 de diciembre de 2020

\section{Estiven Valencia Marín}

\section{Resumen}

La búsqueda de lo divino, que aparece en el cristianismo como un asunto espiritual, perfila ser tema de importancia para una mística agustiniana que tiene referencias a la figura de Dios, esto es, expresiones que intentan describir la naturaleza divina. Así pues, el santo de Hipona, a través de términos como luz y verdad, presenta los rasgos de un Dios que parece mostrarse tal como es, pero para alcanzar una visión tan inefable, es necesario el deseo de esta; una búsqueda de Dios que, traducida en amor, es un proceso de ascenso a la verdad

a Este artículo es resultado de un ejercicio de profundización a partir de una propuesta de ponencia en torno a la noción filosófica de erotismo y su sentido místico en la patrística, particularmente en la figura de Agustín de Hipona, desarrollada para el II Coloquio Interinstitucional de Patrología que tuvo lugar en la Fundación Universitaria Cervantes de Bogotá.

* Licenciado en Filosofía y Educación Religiosa, Universidad Católica de Pereira, Pereira, Colombia. Miembro del grupo de investigación del Fenómeno Religioso en la línea de Filosofía y Religión, Universidad Católica de Pereira. Contacto: steven01051991@hotmail.com, ORCID: https://orcid.org/0000-0001-9652-7701 
de lo divino permeado por ese intenso deseo de ello. De manera que un deseo de Dios posiblemente connota una erótica entendida como amor vehemente; el cual, para interés del presente artículo, puede resignificar la noción común de erótica y de sexualidad inherentes al carácter relacional del ser humano, a veces visto con sospecha.

\section{Palabras clave}

Amor cristiano; Erótica; Mística; Ordo amoris; Sexualidad; Teología espiritual.

\section{Abstract}

The search for the divine, which in Christianity is an important spiritual theme, for an Augustinian mysticism seems to refer to the human vision of God that is possible to be described. Thus, the saint of Hippo through terms such as light and truth, presents the features of a God who shows himself, but such an ineffable vision requires of the desire; a search for God that translated into love becomes process of ascent to the truth of the divine permeated by that intense desire. So that a desire for God possibly connotes an eroticism understood as vehement love and which for interest of article can resignify the common notion of eroticism and sexuality inherent in the relational character of the human being, sometimes so suspicious.

\section{Keywords}

Spiritual theology; Erotic; Mystic; Christian love; Ordo amoris; Sexuality. 
Tú eres mi Dios; por ti suspiro día y noche, y cuando por

vez primera te conocí, tú me tomaste para que viese que existía lo que había de ver, y que aún no estaba en

condiciones de ver.

(San Agustín, ca. 397 d.C./1974, . VII, 10)

¿Qué amor es el que hace hermoso al amante? Dios es hermoso. Amó primero el hermoso ¿Y a quienes amó sino a feos? Pero amó para hacerlos hermosos.

(San Agustín, ca. 407 d.C./1959, IX, 9)

Dentro de las definiciones de ser humano que en el desarrollo de la historia se han alcanzado, sus caracteres 0 atributos comportan un soporte descriptivo orientado a una proposición conceptual general. Instintos, necesidades, gustos y facultades en conjunto encauzan las más vastas explicaciones y, sin embargo, la concreción de una posible aclaración del ser del hombre es potencialmente resignificada. A propósito, el deseo constituye ineludiblemente al hombre; deseo que, comprendido como un interés por poseer o realizar lo que considera objeto de su bienestar, está determinado por sentimientos nobles 0 abyectos que lo preceden. En tal caso, lo divino se inserta entre los considerados bienes a los que se accede por necesidad de compleción del proyecto existencial, empero, alcanzar este supone una previa búsqueda con miras a satisfacer el deseo de plenitud.

La búsqueda de lo divino aparece explícita en Agustín de Hipona, una figura insigne en el ámbito teológico quien, en su serie autobiográfica Confesiones, depara un amplio itinerario en orden a la contemplación de Dios. En lo que respecta a esta contemplación, que es un fin en sí, el anhelo le precede como un sentimiento motriz identificado con el concepto de amor que es expuesto por el 
hiponense (Arendt, 2001, p. 25), entendido así también en el acervo platónico1. No obstante, semejante amor 0 anhelo que puede proceder de un recuerdo de placeres vividos, se genera también en las potencialidades que el ser humano confiere a cualquier objeto de su interés. Análogo a esto, la erótica, que significa un amor vehemente, guarda relación no solo con lo sexual, sino también con un gesto de atracción por un objeto o meta de lo que se presupone nexos con la búsqueda de Dios.

Así las cosas, un proceso de ascenso a la verdad de lo divino, permeado por el intenso amor a ese fin, connota posiblemente una erótica que es preciso mostrar para revelar la entrañable relación entre amor cristiano y un erotismo resignificado. Para ello, el tratamiento de la acepción de amor declarada por la tradición teológica agustiniana con base en su obra Confesiones ${ }^{2}$, seguido de una exposición referida a la noción de sexualidad que alberga el pensamiento cristiano, permitirá reconstruir relaciones conceptuales que permitan hablar de una estimación erótica en la mística agustiniana. Respecto de la sexualidad, de antemano vinculada con lo erótico, cabe señalar que, en la perspectiva del cristianismo, no solo la realidad psicofisiológica y biológica se le adecúan, sino que, además, manifiesta rasgos tan esenciales como el coexistir y relacionarse con los demás (Wojtyla, 1969, pp. 49-50).

\footnotetext{
La identificación del amor con el deseo, tan claramente cultivada en el pensamiento de San Agustín como en otros muchos pensadores cristianos, se ve expresada con antelación en el pensamiento platónico. A grandes

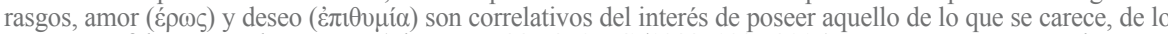
que se está falto según el Banquete (Platón, ca. 385-370 a.C./1988, 199c-201c). Este argumento se prolonga en

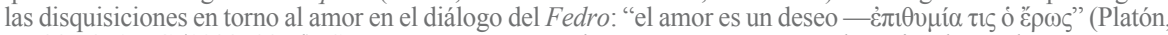
ca. 385-370 a.C./1988, 237d). Se anexa a ese amor y deseo un parentesco con la amistad, mas los tres poseen una inclinación al bien según lo dicho en el Lisis (Platón, ca. 393-389 a.C./1985, 219c-221c). Sin embargo, la diferencia existente entre el $\varepsilon \rho \omega \varsigma$ y $\varphi \imath \lambda i ́ \alpha$ — traduce este por amistad — radica en el máximo grado de intensidad o violencia que el primero ejerce tal cual se indica en Leyes y Ética a Nicómaco (Platón, ca. 348 a.C./1999, VIII, 837a; Aristóteles, ca. 349 a.C./2009, 1117a 11-12), razón por la que quizá las reflexiones filosófico-cristianas

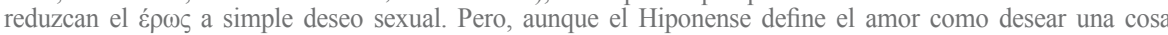
(appetitus) según lo expresa en Ochenta y Tres Cuestiones Diversas (San Agustín, ca. 389 d.C./1995, 35, 1-2), ese deseo o amor se usa en un buen sentido cuando se destina a la voluntad recta (voluntas recta), y tiene mal sentido cuando se destina a la voluntad perversa (voluntas perversa) según lo dicho en Ciudad de Dios (San Agustín, ca. 426 d.C./1958, I, VII, 2).

Aunque en Confesiones existen perícopas sobre experiencias místicas, definiciones sobre el amor a Dios, se tienen también en obras como Soliloquios, Ciudad de Dios y Diversis Qucestionibus. Para interés del presente estudio, se estima tratar los libros VII, IX y X de Confesiones, usando la edición crítica de Ángel Custodio Vega (1974) de la BAC.
} 


\section{Sapientia amoris en la teología agustiniana}

A consecuencia de las relaciones que el individuo establece con su medio social y natural, las representaciones que hace del mundo y de experiencias vividas definen el aspecto formal de toda esfera del conocimiento. Mejor aún, en su intento por entender lo que le acontece, así como preguntarse por sí mismo, el hombre en actitud reflexiva adopta elementos de posible elucidación relativos a su identidad, $y$ a la vez, explora patrones de conducta con el fin de orientarse en tal comprensión. $Y$ aunque el saber sobre la identidad y el sentido de la existencia de una persona concreta alude a un modo genuino de conocimiento, aesto se vincula una inquietud que se adquiere por el incompleto desvelamiento del ser dentro del mundo. Ilusorio o no, comprender el mundo y la persona en su individualidad conserva un sentido existencial que integra la búsqueda de plenitud en todo ser humano.

En lo referente a la indagación por la identidad y el sentido existencial de la persona, la inclusión de la felicidad comporta un rasgo esencial en tanto esta es el fin de todo esfuerzo humano. De manera que, dada a los hombres como tendencia natural, la felicidad identificada con idearios de bienestar, plenitud, entre otros, equivale a estados únicos; una secuela de acciones y apetencias personales que significan un proceso subjetivo, pero que, al tratarse de un atributo común a todo ser humano, se torna universal (San Agustín, ca. 397 d.C./1974, X, 20, 29). De modo parecido al enigma del hombre en sí mismo, coexiste con la felicidad una inacabada intelección; trátese de múltiples acepciones que figuran en el concepto o por la ambivalencia práctica entre el bien querido y las acciones que conducen a tal fin, pero lo que resulta cierto es el posible asirse el hombre de la verdad como objeto de felicidad.

Sea lo que fuere, independientemente de los medios que el hombre procura para la consecución de lo que considera bienestar suyo, busca también de la verdad como su bien. Ante esto, el conocimiento del ser propio del hombre y la elucidación del sentido de la vida que estima la pregunta por su origen y 
fin, en tanto encauzada en Dios, son cuestiones que en De Ordine ${ }^{3}$ se resuelven como atisbo de verdad, es decir, capacitan para entender el orden de las cosas (San Agustín, ca. 386 d.C./1969, II, 18, 47). Existe pues en toda estructura del conocimiento un factor inexorable de verdad por cuanto se identifica con el ser de las cosas: verdad es lo que es, asociada tanto a lo inteligible como lo sensible, y a la vez goza de carácter universal por considerársele, según lo expuesto en Soliloquios, como dada a todos los seres humanos sin estar sujeta a imposiciones de los individuos (San Agustín, ca. 386 d.C./1969, II, 5, 8).

Baste todo lo anterior para señalar el posicionamiento de la verdad como fin de la vida feliz: "beata quippe vita est gaudium de veritate" [la vida feliz es gozo de la verdad] (San Agustín, ca. 397 d.C./1974,X, 23, 33), mas esa comprensión del medio en que el hombre se desenvuelve y lo trascendente que a él le compete, suponen dos tipos de saber. En primer lugar, el saber de lo sensible, o ratio inferior, sometido a las sensaciones, las cuales informan de lo externo a la persona que constituye el medio con el cual este se relaciona. Y, en segundo lugar, el saber intelectual, o ratio superior, que apropia el descubrimiento de sí mismo y las ideas universales como elementos más próximos a la verdad, siendo esto el efecto de un proceso de introspección que exige al alma apartarse de lo externo (San Agustín, ca. 386 d.C./1969, I, 14, 24), si bien se busca de la sabiduría humana que no está propiamente en las cosas:

La sapientia encierra una relación esencial con la felicidad del hombre: no es conocimiento especulativo que afecte solo al entendimiento, es actividad integral que interesa a toda el alma. Ya la cognitio scentialis dirige la acción al sumo bien, pero la

Sobre el Orden es una de las obras tempranas del pensador converso, Agustín, en la cual deja ver el universo como un vestigio divino, hechura de Dios, además del sondeo de las realidades interiores y espirituales: el alma del hombre y Dios, tan característico del obispo de Hipona en sus muchas otras obras. Los demás escritos de San Agustín que corresponden también a este periodo temprano en que se retira a la Villa de Casiciaco tras su conversión al cristianismo, a saber: Soliloquios y Sobre la Vida Feliz, serán objeto de referencia para el presente estudio. 
contemplación en su último grado es el sumo bien del hombre. Por eso la contemplación de los inteligibles puros en esta vida no se consigue por el mero ejercicio del entendimiento, exige la pureza de corazón. (Alesanco Reinares, 2004, p. 96) ${ }^{4}$

Por lo que sigue a los tipos de saber, la razón como facultad asociada a la actividad del pensamiento hace las formas de interpretar, aprehender y obrar acorde a los precedentes conceptuales que emergen de la experiencia o la intelección. De ahí que conceptos como los de alma y Dios, dados en la intimidad de la conciencia, y a los cuales el hiponense hace objetos de saber tal cual presenta en Soliloquios (San Agustín, ca. 386 d.C./1969, I, 2, 7), desbordan lo sensible y trascienden a la razón por cuanto escapan a una absoluta comprensión tratándose de nociones inteligibles. Pero tales nociones, por su talante incorpóreo y eterno, no dependen del sujeto pensante, sino del summum veritatis necesario y eterno: Dios. Así pues, de Dios deriva todo cuanto de verdad hay (San Agustín, ca. 386 d.C./1969, I, 1, 3) ora en el plano sensible ora en el inteligible; verdad que aprehende la mente sin ser ella productora de aquella verdad:

El punto base absoluto sobre el que se apoya la filosofía agustiniana es que la mente humana conoce lo verdadero, pero no crea la verdad, sino que existe en sí y es Dios. Pero precisamente porque la mente humana no crea a la verdad, que preexiste eterna y trasciende, y sin embargo conoce la verdad, se deduce que es partícipe de la verdad. Por tanto, la verdad como contenido de la mente divina, está presente en la humana de manera distinta. (Sciacca, 1955, p. 266)

De hecho, lo que de verdad capta toda persona y trasciende a lo meramente material dada su procedencia divina, parecido modo guarda con esa

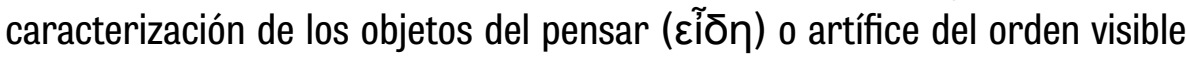

\footnotetext{
${ }^{4}$ Saber científico, contemplación del summum bonum y purificación del corazón suponen en conjunto un proceso que propende por la asimilación de Dios como verdad absoluta; alta expresión de la felicidad para el hombre. De hecho, la cognitio scentialis — saber científico- que al decir del obispo hiponense en su De Trinitate, guarda relación con las cosas temporales y mudables (San Agustín, ca. 417 d.C./1956, XII, 12, 17), tiene parte en la razón cuya función es discernir y enlazar lo que conoce tal como sostiene en De Ordine (San Agustín, ca. 386 d.C./1969 II, 11, 30), pero también es la razón la que dota el alma de capacidad para orientarse en el conocimiento de Dios. Se trata, entonces, del proceso de ascenso que estima en el deslinde de la experiencia sensible, la posibilidad del conocimiento divino; deslinde aquel que se traduce en términos de purificación del sentido del alma — sensus animoe - como se indica en Soliloquios (San Agustín, ca. 386 d.C./1969, I, 6, 12). Existen, pues, coincidencias entre la descrita noción del ascenso ontológico con la de las filosofías platónica y plotiniana: contemplación de la idea de belleza (Banquete 210a-211d), del Bien según República (Platón, ca. 370 a.C./1986, VII, 517b-c; 532b) y del Uno o Bien según Enéadas (Plotino, ca. 270 d.C./ 1998, VI, 7, 15; VI, 9, 7, 5-20). Por lo demás, la verdad divina, objeto inteligible e incorpóreo en tanto viene de intelección como se indica en el Tratado sobre la Trinidad (San Agustín, ca. 417 d.C./1956, XII, 14, 23), constituye el maridaje sabiduría-felicidad que son las condiciones de la realización del hombre según lo expuesto en Sobre el Libre Albeldrio y Confesiones (San Agustín, ca. 386 d.C./1969, II, 9, 26; ca. 397 d.C./1974, X, 22, 32; 23, 23).
} 
(סฤuıoupyós) que perpetuó la tradición platónica. Tales ideas merecieron el interés del hiponense (San Agustín, ca. 397 d.C./1974, VII, 9, 13), pero esto no significó una completa adhesión a lo anunciado por los legatarios del platonismo. Así, una dialéctica intelección-pasiones manifiesta en San Agustín es la que tanto Platón como Plotino hicieron camino de ascenso a la verdad, al bien, a la belleza, a la sabiduría (Morales Troncoso, 2017, p. 4). No obstante, la noción de Dios como único absoluto es lo que distingue a Agustín de sus predecesores griegos. Por tanto, el afán de conocimiento y contemplación de Dios que, desde Agustín de Hipona, se estiman por sabiduría, tiene de base el deseo de tal fin.

En cuanto al deseo, modo originario del ser del hombre -que si bien se funda en el anhelo (appetitus) de poseer un bien, esto es, la experiencia de necesidad que acontece a la falta de algo 0 alguien- para el hiponense el objeto 0 fin que lo determina puede ser causante del gozo permanente, 0 en su defecto, del gozo efímero. Los honores, riquezas, la complacencia en mujeres, el gusto por los manjares y bebidas que, al tratarse de bienes sujetos a la realidad externa, son diferentes de la soberana hermosura incorrupta (vehementer aestuo pulchritudinis) que es fin de un verdadero amor tal cual expuesto en De Beata Vita (San Agustín, ca. 386 d.C./1969, X, 17). De manera que, un direccionamiento de la vida con el propósito de conocimiento de Dios aparece como amor benevolente o de caridad por el que se es feliz, contrario al concupiscente que tiene su hacedero en las cosas creadas (San Agustín, ca. 386 d.C./1969, IV, 34).

Se establece, entonces, el deseo 0 amor como un estímulo ineludible de la búsqueda del bien, de la propia felicidad, in stricto sensu de Dios mismo, quien porta el mayor de los gozos: "beata vita est gaudere de te, ab te, propter te" [vida feliz es gozar de ti, para ti, por ti] (San Agustín, ca. 397 d.C./1974, X, 22, 32). En consecuencia, un gozo estable, seguro y permanente es el que tiene quien desea o busca de Dios tal cual se indica en De Beata Vita, contrario a la insatisfacción que producen aquellos bienes de fortuna y mundanos (San Agustín, ca. 386 d.C./1969, II, 11). De aquí que sea el amor, ora tributario de bienes terrenos o bienes trascendentales, el que transforma las condiciones de vida del hombre en tanto prefiguran la adquisición de felicidad o infelicidad, es decir, por 
inclinación a lo material y temporal se arriesga el hombre a perder estabilidad ya que los bienes terrenos son cambiantes, pero optar hacia lo divino trae el bien eterno.

De esta suerte es como el amor moviliza al hombre en su ansia de conocer, apropiar y apreciar todo cuanto se propone como fin, por ende, condiciona sus actos y les da valor de ser nobles o laxos, sobre todo porque el problema recae sobre los objetos deseados. Desde esta perspectiva, concupiscencia y caridad relativas a la apetencia de lo mundano y de Dios respectivamente, declina en efectos positivos o negativos para el hombre supeditado por sus deseos, tal como sostuvo Arendt (2001): "el ansia de mundanidad transforma al hombre en un mundano, en la concupiscencia abraza el hombre lo que le hace perecedero, y en la caridad cuyo objeto es eternidad el hombre se hace un ser eterno" (p. 36). En esencia, voluntad y subsecuentes actos orientados por amor a lo divino, están a la base de una querida sabiduría que es, sin más, el gozo pleno que procede de Dios.

\section{Misticismo en las Confesiones de Agustín de Hipona}

Una previa intención de gozarse en Dios comporta el impulso hacia lo trascendente según lo expuesto con anterioridad, intención o deseo de contemplación divina que es la felicidad, pero demanda depurar ideas obcecadas que obliteran un acceso a la verdad en tanto es Dios. Parte de este proceso se manifiesta en la creencia de una aproximación a lo divino por un ejercicio taxativamente racional que amparó el obispo de Hipona (San Agustín, ca. 397 d.C./1974, III, 3-6) como un acto posterior a la vida libidinal que vivió en su adolescencia, pero también esto implicó el abandono de su adhesión a una creencia maniquea en tanto pesquisa exasperada de la verdad tras su encuentro con el cristianismo tal como lo expresa en sus Confesiones (San Agustín, ca. 397 d.C./1974, V, 13-14). Con lo dicho, las prácticas descritas que integran una etapa de purificación y contiguo itinerario de ascenso a lo trascendente, todo so pretexto de unión con el sumo bien, lo sagrado, lo divino, descubren una eximia mística. 
En ese proceso de asunción a Dios, un consentimiento presto a la fe como vía segura completa lo que por raciocinio se mienta de lo divino, pero en reparo de una fatua concepción de lo sagrado como simple idea del hombre racional es Dios quien por voluntad propia se manifiesta a quien lo busca. De ahí que la experiencia contemplativa dada en el descubrimiento de Dios desde la interioridad humana es causada por la actuación divina porque, según el hiponense, su experiencia mística se debe a la ayuda y la guía que Dios mismo le procura (San Agustín, ca. 397 d.C./1974, VII, 10,16), así como la posibilidad de discernimiento y un control de los sucesos por parte del ser humano dependen de Dios (San Agustín, ca. 397 d.C./1974, IX, 10, 23). En esencia, el quærere Deum en tanto estadio inicial a la visión de Dios se funda en lo sobrenatural que con auxilio de la divinidad ( $g r a t i a$ Dei) alcanzan para el hombre el fin de la contemplatio Dei.

El Hiponense, fiel a la doctrina que acogió tras su vínculo con el cristianismo, declaró la existencia e inmutabilidad divinas, además de atribuir a Dios providencia, justicia y salvación como virtudes que refieren a Él según presenta en Confesiones (San Agustín, ca. 397 d.C./1974, VII, 7, 11) y aunque, dado este asentimiento, sus convicciones se vieron aún debilitadas por cuestiones irresueltas. Este es el caso de problemas que se plantea el mismo Agustín como el origen del mal o la representación corpórea de Dios (San Agustín, ca. 397 d.C./1974, VII, 1-3), problemas que restringen su aspiración a una vivencia directa de Dios dada una abstrusa comprensión de lo sagrado que se cimentó por controversias personales. Bajo tales condiciones, el proceso reflexivopurgativo de corazón y mente, deseos e ideas, se hace necesario como medio para encauzar la búsqueda de la verdad, la unión con el sumo bien, y cuyo desarrollo está en la interiorización:

La indagación por la verdad es un empeño de todo el espíritu, de todo el hombre. Para Agustín el proceso de sabiduría se identifica con el proceso de nuestro espíritu; los grados del saber son los de la espiritual elevación, es conquista de una interioridad profunda: interiorizarse para trascender. Buscar, filosofar, es aprehender la verdad en el interior, es decir, adquirir el conocimiento del alma y de Dios. (Sciacca, 1955, p. 150) 
Entonces la interiorización, además de ser una experiencia que se asegura en las necesidades de una persona para, con ello, pensar los medios que alcancen la solución a sus privaciones, también se presenta, en términos de Bataille (citado por Abad Montesinos, 2016), como la vía de confrontación con la finitud de sí mismo, con aquella existencia henchida de inquietudes y problemáticas que la caracterizan. Claro es el nexo que existe entre la experiencia de interiorización que, hasta ahora, el mismo Agustín relata y la definición que de ella ofrece el ya referido autor contemporáneo despojándola de confesionalidad alguna (Bataille, 1973, p. 13). Sin embargo, dicha experiencia desnuda y libre de ataduras que cuestiona e indaga por lo vivido, y porta lo desconocido, lo que supera a las limitaciones, perfila ser el medio para un vínculo 0 aproximación con lo que el ser humano estima sagrado.

En efecto, el descubrimiento de lo sagrado que acontece en el ascenso de lo sensible a lo trascendente es un conocer singular dado el rasgo sobrenatural que posee, es decir, sobrepasa a la razón (Alesanco Reinares, 2004, p. 391). Pero todas las cuestiones aún irresolutas por las cuales la mente pierde vuelo y se torna oscura e inmovilizada (San Agustín, ca. 397 d.C./1974, V, 14, 25) -asimismo, como relata el autor en cuestión, queda cautivo de jactancia por la ciencia (San Agustín, ca. 397 d.C./1974, VII, 20, 26), de negocios seculares y ligado al goce mientras es aprendiz del cristianismo (San Agustín, ca. 397 d.C./1974, VIII, 6, 13) - hablan de la mirada limitada e imperfecta de lo sagrado, de Dios mismo. Por ello, retornar a la interioridad de sí con el objeto de discernir sobre aquellas presuntas verdades arraigadas, acontece como imperativo que permite hacerse con la verdad de Dios, esto es, purificar más al alma para una contemplación de lo divino.

Una práctica purgativa en San Agustín que parece reflejarse no solo en una ascética que le permite sortear aquello que puede obstaculizar la aceptación de la fe cristiana, además de comprometerse con la resolución de controversias de fe que obturan la recta comprensión de Dios, pueden darse como un itinerario que dispone al hombre para la visión beatífica de lo divino. A esto se añade la profundización del deseo conveniente a dicha contemplación, sin ignorar la práctica de las virtudes que encarna la aprehensión de una fe pensada y, por demás, meditada (Velasco, 2003, p. 303), y descubre aquello que 
debe ser perseguido como fuente segura de verdad. Claro es, entonces, para el obispo de Hipona que, el estado cambiante y condición creatural del mundo, además de sus objetos, no son Dios tal como lo presenta en sus Confesiones (San Agustín, ca. 397 d.C./1974, X, 6, 9), mas dicha convicción solo es descubierta por el hombre desde su interior:

La doctrina y experiencia espiritual de San Agustín está dominada por un reclamo persistente a la interioridad. El hombre vale por lo que es, en su intimidad, delante de Dios quien lee los corazones; en el hombre interior habita la verdad y el Espíritu Santo edifica allí el templo de Dios. Por ello, necesario es que el hombre entre en sí mismo para después elevarse y hallarse con Dios; es el hombre quien crece en su ser cuando aumenta el caudal del espíritu. (Capanaga, 1974, p. 214)

Ya presto el hombre en su interioridad, ${ }^{5}$ allí donde se escruta la realidad del alma y todo juicio que se predica acerca del mundo y sus fenómenos, sucede como una actividad anímica. Ahora, dentro de sí, los recuerdos, imágenes y pensamientos que se olvidan, cambian o se ignoran son insuficientes para revelar a Dios: "in recessus memoriæ meæ plena miris modis nihil eorum te esse inveni" [en mi memoria llena de muchas riquezas, ninguna de ellas eres] (San Agustín, ca. 397 d.C./1974, X, 40, 65), pero, también, las pasiones, sentimientos y deseos que allí residen se convierten en objeto de discernimiento. En efecto, al examinar el mundo y el pensar propio como un ejercicio de introspección, aquello que se valora como inmutable y eterno en el alma no viene de lo externo, ni del interior del hombre como simple acto de racionalidad, sino que se posa en él pues le viene de más allá de sí.

Tal es el modo en que, retornando al alma y examinando las actividades de esta, se descubre a Dios, en otras palabras, es en la interioridad, en la región de la fe y el entendimiento que San Agustín acomete la tarea de buscar a Dios, buscar la causa del existir y definirse a sí mismo (Leal, 2014, p. 167). Depurada esta alma de toda noción material, de todos los elementos que le hacen perecer,

\footnotetext{
La experiencia mística o arrobamiento que acontece en el interior se ofrece como posibilidad de trascendencia considerando que es allí mismo donde sucede la actividad del pensamiento y, no obstante, esta actividad puede limitarse a lo que los sentidos proporcionan en tanto conocimiento del mundo. Es el caso de Pseudo Dionisio Areopagita en Sobre los Nombres Divinos, como el de muchos otros místicos cristianos, para quien conocer a Dios es un hecho de trascendencia del pensamiento por el que se espera su presencia: "conociéndolo más que por ciencia teórica, por experiencia personal de lo divino-non solum discens, sed et patiens divina" (Dionisio Areopagita, ca. 533 d.C./2007, I, 1). En cuanto al obispo de Hipona, San Agustín, una explicación concreta del proceso de ascenso en el que se estima el paso de lo sensible a lo inteligible, y de lo sensible intuyendo su origen en Dios, se encuentra en Las Confesiones VII, 17, 23.
} 
reflexiona sobre sí misma y conociéndose más tiende hacia Dios al reconocerlo como su origen. Así pues, dispuesto el hombre en dichas condiciones, deviene la unión con lo sagrado, ese encuentro con Dios, encuentro o unión que llega a hacerse explícito dado que se comunica o se predica lo que analógicamente es Dios tal como lo describe el hiponense en Confesiones en los siguientes términos: luz inconmutable, inigualable y enceguecedora (San Agustín, ca. 397 d.C./1974, VII, 10, 16), única verdad (San Agustín, ca. 397 d.C./1974, X, 26, 37; 40, 65), tan cierto como el mundo que percibimos y la vida misma (San Agustín, ca. 397 d.C./1974, VII, 10, 16).

Para abreviar, una experiencia contemplativa, desde Agustín de Hipona, se debe a la actuación divina (gratia Dei), si bien es Dios quien dota de los medios para ello y proporciona las circunstancias que la adecúan, además de aquel empeño que el hombre presta por medio de ascesis para hacerse con esta finalidad. Dicho de tal modo, la exoneración de mediación material 0 racional para el conocimiento de Dios es la razón que justifica la potestad divina para revelarse, para generar un encuentro con su criatura. De hecho, la experiencia mística revela al hombre una presencia de lo divino, una presencia de Dios en su interior (Velasco, 2003, p. 325); mística esta que significa el proceso en que el hombre, en su alma, asciende desde las cosas y actos a lo sagrado, entablando así una relación con lo trascendente, con Dios que es fuente de la felicidad deseada, de la felicidad amada.

\section{Apreciación cristiana de la sexualidad y nexo erótico}

El cristianismo - que en su trato con la filosofía procuró valiosas interpretaciones en diversos asuntos que urgen de las más prolijas reflexiones- trajo consigo una nueva visión relativa a la sexualidad. Es caso típico la inserción del concepto de persona como novicia forma de entender el ser humano en su singularidad y multiplicidad de dimensiones, en desdoro a los enunciados materialistas, consumistas y tecnicistas de la era moderna que ostentan reducir el ser humano a facetas triviales contra una óptica omniabarcadora de los individuos. De ello resulta la sexualidad como aspecto esencial de la existencia, igual a la moral y la trascendentalidad en tanto dimensiones identitarias de los seres humanos que, a 
grandes rasgos, condicionan la capacidad de estos para relacionarse con sus semejantes, consigo mismos y con el medio que habitan, el medio en el que se insertan desde el nacimiento.

Bajo esta perspectiva personalista, la sexualidad no solo condiciona los atributos físicos y comportamentales de los sujetos, sino que también entraña algún tipo de vínculo, en otros términos, es la expresión de convivencia que contrasta con una coexistencia inerte entre individuos (Marías, 1970, p. 164). Tal rasgo relacional se circunscribe a la faceta afectiva de toda persona en tanto dimensión que informa sobre la reacción humana ante los aconteceres del mundo, reacción esta desde la que se forman las percepciones y las valoraciones del medio que le rodea. De todos modos, la sexualidad y la afectividad, cuyo criterio común es la relacionalidad, no se conocen sin la corporalidad, puesto que las percepciones, al igual que las emociones en tanto exhibición de aprehensión y estimación de mundo, residen en los individuos que experimentan en su cuerpo percepciones y emociones:

Las percepciones ligadas al conocimiento acontecen porque los sentidos reaccionan frente a los objetos adecuados por medio de las sensaciones discernibles al interior de la percepción (...) pero la emoción, aunque es también reacción sensorial provocada por un objeto, su contenido difiere del de la percepción. En el contenido de esta se da la imagen del objeto, mientras que en la emoción se experimenta el valor dado a los objetos. La percepción es la reacción ante las propiedades, mas la emoción es la reacción ante los valores. (Wojtyla, 1969, pp. 110-111)

Todo el complejo psíquico relacionado con el plano afectivo -las emociones, motivaciones, pasiones, deseos, estados de ánimo - se ve implicado en la construcción de personalidad de todos los individuos. De hecho, las actitudes y pensamientos, sentimientos y conductas precedidos de deseos, de instintos 0 de emociones son respuestas a la gran variedad de situaciones en las que se halla inmerso el hombre. Y, por tratarse estos de estímulos que calan en lo íntimo de todo ser humano, cierto es que configuran la individualidad del mismo. Así pues, la interioridad del hombre en la que se acomoda la personalidad resulta ocasión del obrar y del crear (Guardini, 2000, p. 100), cualidades tales que ejercen una influencia en la sexualidad humana por cuanto configuran la conducta relacional y determinan el desarrollo de cada individuo. 
Al estimar, entonces, una condición sexuada que surca otras dimensiones humanas (ora lo afectivo, lo desiderativo, psíquico, ora lo corporal, cognitivo, social, ético) en la proyección hacia los demás y en el empeño de la persona por entrar en la dinámica de interacción con sus semejantes, es notable una superación de esa definición de sexualidad como satisfacción coital. En general, todo comportamiento y toda relación personal son sexuados, aunque no sexuales (Marías, 1970, p. 214), y dicha relacionalidad se convierte en una necesidad más. Con esta novedad en la idea de sexualidad, cuyo rasgo característico es lo unitivo y lo dialógico, la apertura y donación guarda la posibilidad de plenificación del individuo en la interacción, no solo con los semejantes, sino también con lo trascendente; una relación yo-tú que vislumbra el posible crecimiento personal:

El hombre se abre, se manifiesta. Manifiesta su interior, se compromete, y con ello se arriesga. Mientras fue un sólo sujeto, permaneció reservado para sí, y cuando como un "yo" se refirió al otro como a su "tu" surgió algo nuevo: se comprometió y se atrevió a una relación que puede convertirse en destino. Del mismo modo que el tú, se vio incitado por su parte a entrar en contacto, a comprometerse de una forma u otra: la amistad, fidelidad, el amor, la comunidad de trabajo. (Guardini, 1997, p. 466)

Conceptos como los de amor y amistad, aquí expresados en el marco de una sexualidad cuyo rasgo de apertura se describe en la doble categorización de lo otro-inmanente y lo otro-trascendente, encierran todas las variaciones del componente afectivo del ser humano. Para efectos de interpretación, sea que el amor se trate de sentimiento sucesivo a estímulos del medio, o por causa de las actuaciones humanas en tanto anhelo o deseo, se trata de la realización de las posibilidades humanas, un acto que explaya toda la existencia del sujeto (Wojtyla, 1969, p. 86). De esta suerte, la posibilidad de actuación precedida por sentimientos y deseos que transcurren en la psiquis humana, no solo calan en 
la parte instintiva y biológica del hombre, sino que también retratan lo sublime y virtuoso para los individuos como en el caso del amor que busca y desea el bien para los demás 6 .

Con esta distinción de deseos, algunos por ceder a necesidades biológicas y otros de los que el fin puede ser la promoción de los demás, define aquel amor o deseo concupiscente y benevolente (cupiditas et caritas) que el hiponense enuncia. Esta diferenciación obedece a las preferencias humanas, a un ordo amoris que todo hombre se impone en relación con las realidades de su entorno y se ajusta a lo que considera que debe y no debe amarse (Arendt, 2001, p. 58)7. Empero, la fijación en lo carnal proclive de lujuria (San Agustín, ca. 397 d.C./1974, II, 2, 2) y la neta admiración por lo sensible como presenta el obispo de Hipona en De Ordine (San Agustín, ca. 386 d.C./1969, II, 27) son deleznables porque envilecen una orientación a Dios, envilecimiento que es amor egocéntrico. Y aunque sexualidad se entiende, en San Agustín, como acto biológico y conyugal que tiene por fin la procreación (Alesanco Reinares, 2004, p. 467) la interacción con otros es idea que no pasa desapercibida.

Ciertamente, en términos agustinianos, la sexualidad es aspecto de la vida matrimonial en tanto sociedad procreativa y conyugal de la que depende un orden social más elevado; no obstante, el carácter unitivo que involucra a sujetos, tal cual se valora en las reflexiones cristianas contemporáneas, no solo se estima con miras a la generación de la prole, sino también por el vínculo afectivo entre personas que excede a las relaciones sexuales. En otras palabras,

\footnotetext{
En la tradición cristiana la idea del amor como búsqueda del bien para el otro alcanza similitudes con el ideal ético de la filosofía griega precedente, que estima también el amor como voluntad de querer el bien para alguien. Por una parte, al interior del cristianismo el amor oblativo, contrario al posesivo, dado en San Agustín - benevolentia versus concupiscentia respectivamente - será precisado en la Summa Theologica como preocupación por el bien del otro: "amar es querer el bien para alguien-amare est velle aliquid bonum" (Tomás de Aquino, ca. 1274 d.C./1993, I-II, q.24, a.4). De ahí que el amor por concupiscencia refiere a simples búsquedas de satisfacción convenientes al individuo, contrario al amor benevolente que concede el deseo de cosas para otras personas en la medida en que le son un bien. De otra parte, la ética aristotélica, de la que Tomás de Aquino retoma el concepto de amor oblativo, se trata de la voluntad de querer y hacer el bien a otros según se expone en la Ética a Nicómaco (Aristóteles, ca. 349 a.C./2009, II, 1380b 35). La misma definición de un amor benevolente se puede notar en Etica Nicómaco VIII, 1156a 9, Ética Eudemia VII, 1241a 5-15, y Magna Moralia II, 14.

El orden en el amor designa las condiciones por las cuales se hace posible el conocimiento de la verdad: desear y conocer la verdad, además de distinguir lo que se debe amar. La verdad que es Dios en Agustín no solo estima el conocer la misma, pues el móvil de ello, lo que le precede, es el amor, el deseo de alcanzar la verdad tal como se muestra en Soliloquios (San Agustín, ca. 386 d.C./1969, I, 10, 17). Cabe en este orden el discernimiento de lo que se debe amar por medio de la virtud, disponiendo así de los bienes y refiriéndolos al bien último: Dios, como lo expresa el obispo de Hipona en Ciudad de Dios (San Agustín, ca. 426 d.C./1958, 19, 10). En este caso, la virtud perfila ser el orden más idóneo en el amor en tanto que, por esta, es posible amar bien lo que debe amarse y trae consigo el vivir bien (San Agustín, ca. 426 d.C./1958, 15, 22).
} 
el deslinde entre sexualidad y acto procreativo, siendo este la típica denominación de aquella y destinada también para el concepto de erótica, adquiere sentido más amplio bajo la visión personalista que pone en estima la natural condición sociable del hombre. Por ello, la sexualidad no solo sugiere la cópula, también es condición de ser de todo sujeto de cara a las relaciones que establece con los demás.

Particularmente, el concepto de erótica tuvo por definición el ser un estadio de preparación al acto sexual, estadio que coincide con la ya referida típica noción de sexualidad, pero desde una perspectiva mística estriba en aquella interpelación que los sujetos hacen de sí mismos (Bataille, 1997, p. 33). A esta interpelación que se asume como experiencia interna de la persona le precede un anhelo del hombre por hallar un fin que le defina, esto es, una búsqueda de aquello que ofrezca sentido a su existencia, la búsqueda del paraíso dada la finitud humana que apetece de una vida plena (Zambrano Alarcón, 2012, p. 311). Así, ese deseo 0 apetencia, búsqueda de bien superior 0 aspiración a la verdad, la hermosura y sabiduría, esencialmente, amor a Dios según Agustín, se juzga por erótico a modo de resignificar un concepto que la tradición griega poseía en su léxico (Capanaga, 1974, p. 314).

Al parecer, ciertos autores cristianos recibieron de los griegos la aportación lexical en la que el vocablo ع́ zar aquello de lo que se está falto, concretamente de platónicos y de neoplatónicos que tuvieron gran recepción en el periodo patrístico. Pero la acepción de un encuentro sexual de los cuerpos en que estos pueden asentir a goces 0 deseos desmedidos, incluso dar por sentada la aspiración a una vida sobrenatural que tiene por base el mérito para aquel hombre capaz de trascender su condición finita, revela el contraste entre ideas filosófico-griegas y cristianas (Nygren, 1953, p. 53). En tal entorno, posibles conflictos teóricos abrieron la posibilidad de transformaciones conceptuales, no obstante, está la certeza de una integración terminológica por parte del cristianismo, aunque exista una variación de sentido entre vocablos empleados.

Ahora bien, una pretendida comprensión de sí mismo y una búsqueda de lo que pueda ofrecer sentido a la existencia, si bien desde una óptica cristiana se trata de un itinerario espiritual que integra la fe desde un cuestionamiento 
existencial, no se entiende así en una experiencia interior privada de creencia. Esta idea, lejana de explorar los medios para hacerse con lo divino, para llegar a Dios, más bien es una puesta en cuestión de lo que el hombre sabe por el hecho de existir, de tal modo que en ello no se revela nada (Bataille, 1973, p. 14). Ciertamente, lo que se dice de Dios escapa a las categorías humanas, pero el encuentro con la propia finitud que supera los límites de lo posible e implica la pérdida de fundamentos de saber según Bataille (Abad Montesinos, 2016, p. 24), se iguala a la actitud humilde del yo que, en San Agustín, orienta las acciones en un anhelo de trascendencia.

Las anteriores deducciones acerca del amor a Dios como asunto erótico, en tanto objeto de intenso deseo, pueden parecer pretenciosas, sobre todo en el empleo del concepto de sexualidad que se estima como la relación con el otro, en este caso, sagrado. No obstante, el ahínco de Agustín por la unión con Dios al ir ascendiendo de las fuerzas naturales hasta quien es su Creador, se representa como movimiento del interior de la conciencia que, sin mediación de cuerpos, se asume como efusión mística; el ímpetu del alma que se traduce en erótica (Bataille, 1997, p. 252). Existen, pues, rasgos de una sexualidad que no involucra cópula estrictamente, de modo tal que es posible integrar un horizonte teológico al fenómeno erótico con implicancias afectivas y unitivas que eluden las simples dimensiones biológicas, y por lo mismo, permiten pensar una mística en perspectiva erótica.

\section{Conclusión: erotismo místico en San Agustín}

Al concluir este artículo evocando la idea de erótica para la mística cristiana en Agustín de Hipona, se colige de la resignificación que se le confiere a un concepto tan recelosamente visto por algunos pensadores cristianos, como es el de sexualidad, sin escamotear el desdoro que filósofos griegos de antaño hicieron del mismo por su nexo con las pasiones. De hecho, innegable es la participación de la cosmovisión dual en la comprensión del aspecto sexual que, en últimas, determinó las prescripciones relativas a lo puro e impuro en ello. Sin embargo, la inclusión de afectos, sentimientos y deseos, y la distinción entre relación intersubjetiva y acto coital para la dimensión sexual, tal cual 
fue expuesta por autores del personalismo francés, ofrecen otra forma de interpretar dicho concepto a tientas de una reducida noción biológica y puramente fisiológica.

Resaltan como explicación, de cara al fenómeno dicho, las palabras de Louis Benaert, psicoanalista jesuita para quien la unión sexual ajustada a una mentalidad científica y técnica que le denota como realidad solo biológica, puede simbolizar una unión superior (Bataille, 1997, p. 229). Aquí comienza a advertirse no solo un inédito sentido de sexualidad, si bien la erótica, cuyo enlace con aquella no puede pasar desapercibida, también tiene una nueva consideración. A tal eventualidad se une el uso de términos como deseo, ardor, anhelo, gozo, entre otros, en tanto formas que describen la experiencia erótica; términos que también Agustín osó utilizar, pero se revisó aquí, desde la perspectiva etimológica, que el deseo o el anhelo de Dios se ve reflejado en el

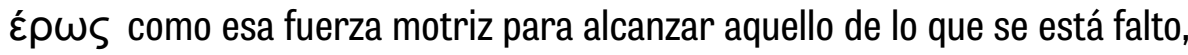
aquello que hace pleno el ser del hombre.

Por lo demás, si bien la pretensión de sabiduría que, al querer de Agustín de Hipona, es la posesión del sumo bien y poseyéndolo alcanza la felicidad (Alesanco Reinares, 2004, p. 396), se arraiga a expresiones que adquirieron un aspecto místico tales como éxtasis, embriaguez, eros, pertenecientes también al léxico de algunos Padres de la Iglesia: Orígenes, Gregorio Niseno y Dionisio Aeropagita (Velasco, 2003, p. 401). Ahora bien, de ese amor apasionado a Dios que mora en la intimidad del hombre y cuyo relato se hizo explícito en las obras aquí tratadas, se armoniza con el pensamiento en tanto búsqueda de sabiduría, por lo cual el intelecto, también movido por amor, purificado del apego a las cosas del mundo y orientado a lo trascendente, es camino a la unión, al diálogo y comunicación con lo divino (Guardini, 2000, p. 117).

Así, la certeza de una vivencia directa de Dios para el creyente, sin la cual la mención de propiedades como luminosidad, verdad, o hermosura divina, no sería posible desde San Agustín. Esto es resultado de un cambio de vida y ascética introspectiva que realizó como estadio previo a la contemplatio Dei. No significa esto que del hombre dependa en total el gozo de Dios a causa del amor o deseo por lo sagrado - quærere Deum—y por la acción de su fe sin más 
porque, como se indicó, es lo divino quien orienta a tal visión como creador del hombre y artífice de posibilidades. Pero el hombre es quien se deja envolver por ese ímpetu de descubrimiento que le permite hurgar los medios para llegar a la plenitud. Así, el ímpetu de descubrir lo sagrado, la apetencia o deseo de gozo estable, la querencia de plenitud y el deseo de Dios revelan una estimación erótica desde la mística agustiniana.

\section{Conflicto de interés}

El autor declara inexistencia de conflicto de interés con institución o con asociación de cualquier índole.

\section{Referencias}

Abad Montesinos, J. (2016). La Comunicación que el Sacrificio descubre: lo Sagrado y la experiencia interior en Bataille. Contrastes, 21(2), 7-25. https://dialnet.unirioja.es/descarga/articulo/5800112.pdf

Aristóteles. (2009). Ética a Nicómaco. (M. Araujo, J. Marías, Trads.). Centro de Estudios Políticos. (Obra publicada originalmente ca. 349 a.C.).

Aristóteles. (1998). Ética Eudemia. (E. Lledó Iñigo, J. Pallí Bonet, Trad.). Editorial Gredos. (Obra publicada originalmente ca. 349 a.C.).

Aristóteles. (2011). Magna Moralia. (T. Martínez Manzano, L. Rodríguez Dupla, Trads.). Editorial Gredos. (Obra publicada originalmente ca. 349 a.C.).

Alesanco Reinares, T. (2004). Filosofía de San Agustín. Editorial Agvstinvs.

Arendt, H. (2001). El concepto de amor en San Agustín. (A. Serrano de Haro, Trad.). Ediciones Encuentro.

Bataille, G. (1973). La Experiencia Interior. (F. Savater, Trad.). Taurus. 
Bataille, G. (1997). El Erotismo. (M. P. Sarazin, Trad.). TusQuets.

Capanaga, V. (1974). Agustín de Hipona. Maestro de Conversión Cristiana. Biblioteca de Autores Cristianos.

Dionisio Aeropagita. (2007). Sobre los Nombres de Dios. (T. Martín, Trad.). Biblioteca de Autores Cristianos. (Obra publicada originalmente ca. 533 d.C.).

Guardini, R. (1997). La Existencia del Cristiano. (A. Lopez Quintas, Trad.). Biblioteca de Autores Cristianos.

Guardini, R. (2000). Mundo y persona. Ensayos para una teoría cristiana del hombre (F. González Vicen, Trad.). Ediciones Encuentro.

Leal, H. (2014). Autognosis en las Confesiones de San Agustín. Veritas. Revista de Filosofía y Teología, (31), 161-78. https://scielo.conicyt.cl/pdf/veritas/n31/art08.pdf

Marías, J. (1970). Antropología Metafísica. Editorial Revista de 0ccidente.

Morales Troncoso, D. E. (2017). La dialéctica del platonismo y la visión de San Agustín en 0stia Tiberina. Acta Scientiarum Education, 39(1), 1-8. https://doi.org/10.4025/actascieduc.v39i1.32601

Nygren, A. (1953). Agape and Eros. The Westminster Press.

Platón. (1988). Diálogos III. Fedón, Banquete, Fedro. (C. García Gual, M. Martínez Fernández, E. Lledó, Trads.). Editorial Gredos. (Obras publicadas originalmente ca. $385-370$ a.C.)

Platón. (1985). Diálogos I. Apología, Critón, Eutifrón, Lisis, Cármides, Hipias Menor y Mayor, Protágoras. (J. Calonge, E. Lledó, C. García Gual, Trads.). Editorial Gredos. (Obras publicadas originalmente ca. 393389 a.C.).

Platón. (1999). Diálogos IX. Leyes VII-XII. (F. Lisi, Trad.). Editorial Gredos. (Obra publicada originalmente ca. 348 a.C.). 
Platón. (1986). Diálogos IV. República. (C. Eggers Lan, Trad.). Editorial Gredos. (Obra publicada originalmente ca. 370 a.C.).

Plotino. (1998). Enéadas V y VI. (J. Igal Alfaro, Trad.). Editorial Gredos. (Obra publicada originalmente ca. 270 d.C.)

San Agustín. (1969). Primeros escritos. (V. Capanaga, Trad.). Biblioteca de Autores Cristianos. (Obra publicada originalmente ca. 386 d.C.).

San Agustín. (1974). Confesiones. (A. Custodio Vega, Trad.). Biblioteca de Autores Cristianos. (Obra publicada originalmente ca. 397 d.C.).

San Agustín. (1959). Exposición de la Epístola de Juan a los Partos. (B. Martín Pérez, Trad.). Biblioteca de Autores Cristianos. (Obra publicada originalmente ca. 407 d.C.).

San Agustín. (1956). Tratado de la Santísima Trinidad. (L. Arias, Trad.). Biblioteca de Autores Cristianos. (Obra publicada originalmente ca. 417 d.C.)

San Agustín. (1995). Cuestiones Diversas. (T. Madrid, Trad.). Biblioteca de Autores Cristianos. (Obra publicada originalmente ca. 389 d.C.).

San Agustín. (1958). La Ciudad de Dios. (J. Moran, Trad.). Biblioteca de Autores Cristianos. (Obra publicada originalmente ca. 426 d.C.).

Sciacca, M. (1955). San Agustín. (U. Álvarez Díez, Trad.). Luis Miracle.

Tomás de Aquino. (1993). Summa Theologica. Parte I-II. (Á. Martínez, D. Gonzáles, V. Rodríguez, L. López de las Heras, Trads.). Biblioteca de Autores Cristianos. (Obra publicada originalmente ca. 1274 d.C.).

Velasco, J. M. (2003). El Fenómeno Místico. Editorial Trotta.

Wojtyla, K. (1969). Amor y Responsabilidad. Estudio de Moral Sexual. (A. Segarra, Trad.). Razón y Fe.

Zambrano Alarcón, M. (2012). El Hombre y lo divino. Fondo de Cultura Económica. 